\title{
A GESTÃO DOS PROBLEMAS ADVINDOS DO RELACIONAMENTO INTERNO EM UMA EMPRESA FAMILIAR, POR MEIO DA MEDIAÇÃO
}

Bruno Barbosa Machado ${ }^{1}$

Henrique Geraldo Rodrigues ${ }^{1}$

Márcia Freire De Oliveira ${ }^{1}$

${ }^{1}$ Universidade Federal de Uberlândia - Faculdade de Gestão e Negócios 


\section{A GESTÃO DOS PROBLEMAS ADVINDOS DO RELACIONAMENTO INTERNO EM UMA EMPRESA FAMILIAR, POR MEIO DA MEDIAÇÃO}

Resumo: Nas organizações familiares, é comum a ocorrência de conflitos entre os gestores que são membros da família e detêm a propriedade do negócio. Assim, o objetivo, neste artigo, foi relatar o processo de mediação realizado numa empresa familiar, com a finalidade de identificar as causas dos conflitos interpessoais entre os membros da família e de propor ações de melhoria. Para o desenvolvimento dessa proposta, foi utilizada a mediação como forma de intervenção, com a finalidade de examinar os problemas e conflitos existentes e orientar a elaboração de um plano de ação a ser adotado pelos membros da família, visando a minimização dos conflitos e a facilitação do entendimento entre os gestores membros da família na tomada de decisão.

Palavras-chave: Empresa familiar. Relacionamento. Conflitos. Mediação.

\section{Introdução}

As empresas familiares podem ser definidas como aquelas em que dois ou mais membros de uma família detêm a propriedade e/ou exercem a gestão da organização e o fundador é também membro dessa família (LEONE, 1991; LONGENECKER, 1997). Diversos aspectos distintivos da empresa familiar são apontados na literatura, em especial, o momento em que ocorre a interação de pessoas de diferentes gerações, normalmente, com o propósito de propiciar a sucessão hereditária na condução dos negócios (DONNELEY, 1967; LODI, 1998).

Entretanto, a forte associação da dimensão empresarial com a familiar pode intensificar o surgimento de conflitos interpessoais que tendem a criar obstáculos ao processo de gerenciamento do negócio (BRITO; SILVA; MUNIZ, 2010). Não obstante o reconhecimento da existência de vantagens nas organizações familiares, como o sentimento de lealdade e orgulho da tradição familiar, os conflitos familiares em relação a fatores como planejamento, liderança, gestão e sucessão são apontados como um dos principais elementos negativos, comumente, presentes no ambiente organizacional de tais empresas (POUTZIOURIS, 2003).

[...] governar uma empresa familiar é saber lidar com toda a complexidade das relações afetivas e financeiras existentes na organização, com as inúmeras diferenças de interesse entre familiares e demais pessoas envolvidas no processo de gestão empresarial e, principalmente, com os inevitáveis conflitos que, não sendo bem administrados, podem levar à destruição de uma instituição. (BORNHOLDT, 2005, p. 83)

A mediação é uma forma de lidar de maneira pacífica com situações de conflitos interpessoais, nas empresas familiares (BARRETO; BARRETO, 2014; CÉZAR-FERREIRA, 2004; MOREIRA, 2011), cujo processo envolve a intervenção por um terceiro imparcial que atua como facilitador da resolução dos conflitos, mediante a indução de entendimentos e acordos entre os envolvidos (KOVACH; LOVE, 2004). A mediação é propícia aos contextos
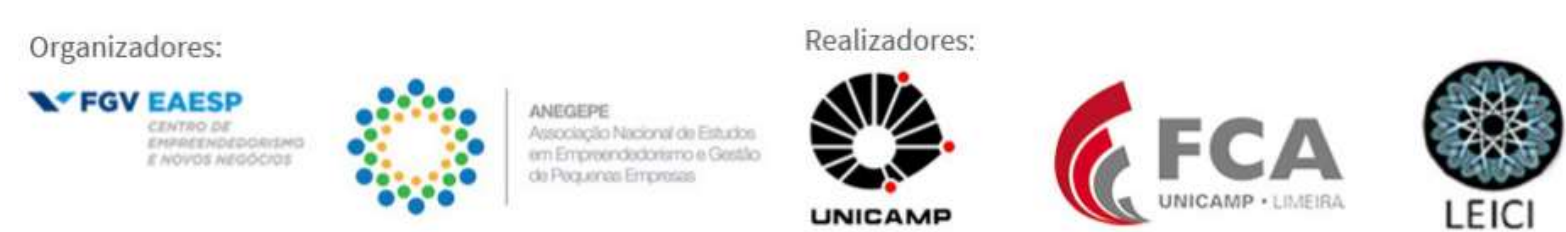
em que as pessoas atribuem importância ao relacionamento, ou não podem renunciar ao convívio com aqueles envolvidos no conflito.

Os resultados oriundos de um processo de mediação bem-sucedido podem abranger, entre outros benefícios, a preservação ou restauração da relação afetiva, social e/ou negocial entre os agentes do conflito, além da elevação da qualidade do processo de tomada de decisões e de resolução de problemas, na organização.

Nessa linha, objetivou-se, neste artigo, relatar o processo de mediação realizado numa empresa familiar, com a finalidade de identificar as causas dos conflitos interpessoais entre os membros da família e de propor ações de melhoria. Para isso, o relato está estruturado da seguinte forma: após esta introdução é feita uma breve contextualização da realidade organizacional investigada; na sequência, é apresentado o diagnóstico da situação-problema; por fim, são feitas a análise da situação-problema e a proposta de intervenção, seguidas das considerações finais.

\section{Contexto e a realidade investigada}

O desenvolvimento das empresas familiares tende a ser impactado pela inter-relação entre as políticas e estratégias organizacionais e os objetivos e interesses dos membros da família, em que a sucessão geracional na propriedade e na gestão é um elemento marcante (DONNELLEY, 1967). Segundo Leone (1991), a gestão da empresa familiar é orientada por três vertentes: a da propriedade, pela qual o comando do negócio fica a cargo da família, detentora e controladora do capital; a da gestão, em que os membros da família devem ocupar os cargos mais estratégicos e, a da sucessão, em que a segunda e subsequentes gerações ocupam os cargos mais altos, anteriormente, ocupados por outros membros familiares. Com isso, modos de agir no ambiente de trabalho e tomadas de decisão podem ser baseados em estreitos laços afetivos e confiança mútua dos membros gestores da família (BERNHOEFT, 1989).

Muitas dessas características são encontradas na ImpreX, empresa familiar com 17 empregados, situada no interior de Minas Gerais que atua no ramo de impressos gráficos desde 1975, quando suas atividades eram voltadas à produção de jornais regionais. Em seus primeiros anos, o nome da empresa era LinoX, devido à utilização de uma máquina de impressão típica da época chamada Linotipo. Com o passar dos anos e com a especialização em produzir convites especiais, foi feita a alteração do nome da empresa para ImpreX, buscando remeter, de forma mais fidedigna, ao que seus proprietários consideram a razão de ser da organização: fazer convites com alto valor agregado para impressionar cada pessoa que os recebem.

A maior parte das etapas do processo produtivo é realizada internamente. Duas etapas gravação de chapas de impressão offset e plastificação e laminação de papéis - são terceirizadas devido aos altos custos envolvidos para sua realização na própria empresa. Além dessas, outras atividades terceirizadas pela organização são: serviços de transporte e frete de mercadorias. Todas as demais etapas do processo são executadas internamente: criação e elaboração da arte final do convite, pré-impressão, impressão, corte e vinco e acabamento final.

A empresa foi fundada por Haroldo e com o decorrer dos anos, sua esposa e seus dois filhos passaram a atuar no negócio. Primeiro, Heloísa, sua esposa, que assumiu a coordenação da função financeira da empresa; depois, seus filhos, Breno e Lucas, que executavam atividades diversas de suporte aos pais. Haroldo praticamente gerenciava todas as atividades sozinho e sempre foi o único tomador de decisões da organização. Ainda que Heloísa fosse a responsável

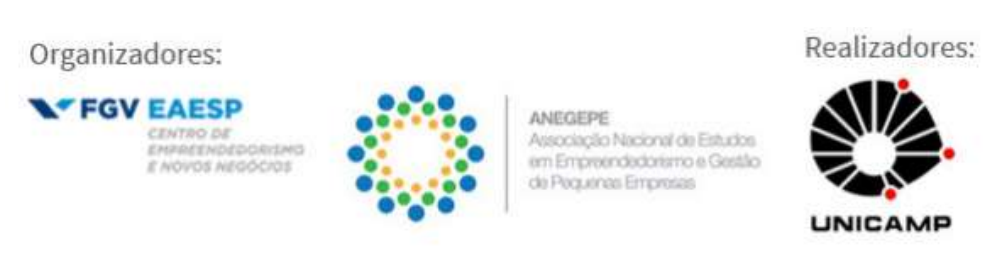


pelo departamento financeiro, nesta área a palavra final também era de Haroldo. Além disso, desde o início do negócio, ele, quase sempre assumia funções operacionais, juntamente com a atribuição de administração da empresa. Ele já havia atuado como operador de máquinas, artefinalista e vendedor, entre outras funções. A falta de profissionalismo da gestão, por vezes, inerente ao processo de gestão familiar (POUTZIOURIS, 2003), podia ser observada em muitos processos e atividades que aconteciam de forma pouco planejada e normatizada.

Em 2015, contudo, ocorreu a sucessão abrupta da propriedade e gestão da empresa para a esposa e os dois filhos, devido ao falecimento de Haroldo, que, pouco tempo antes, havia sido diagnosticado com câncer em estágio avançado. Com isso, os três optaram por distribuir, entre eles, as funções gerenciais do negócio: Heloísa continuou coordenando o departamento financeiro, Breno assumiu a gestão do departamento de produção e Lucas tornou-se responsável pela gestão administrativa da empresa. Com a distribuição da autoridade antes concentrada nas mãos do fundador, havia a expectativa de que uma nova dinâmica gerencial, mais profissionalizada, fosse estabelecida.

Os irmãos Breno e Lucas, apesar da pouca experiência com o negócio, iniciaram, então, um processo de análise e solução dos problemas e dificuldades que a empresa vinha enfrentando. Contudo, à medida que os dois se envolviam com a gestão do negócio e desenvolviam uma interação maior com a mãe, no contexto do trabalho, divergências de opiniões sobre como lidar com as situações de problemas começaram a surgir e levaram ao estabelecimento de conflitos de relacionamento, o que impactou, até mesmo, na interação dos três fora do ambiente da empresa. Por exemplo, era comum que, quando em casa, após o expediente de trabalho, os três retomassem a discussão de questões que não haviam sido resolvidas na empresa, o que, por vezes, gerava novos conflitos e um clima de mal-estar.

\section{Diagnóstico da situação-problema}

No contexto organizacional, são encontrados dois tipos principais de conflitos (MARTINS, ABAD; PEIRÓ, 2014): o conflito de relacionamentos, que consiste nos desacordos das relações interpessoais ligados diretamente a tensão, ao atrito entre os indivíduos do grupo, e o conflito na execução de tarefas, caracterizado pela divergência de ideias e opiniões acerca da execução da tarefa. Caso não seja feita a distinção das emoções durante um conflito de tarefas, esse pode se tornar também um conflito de relacionamento.

Parte dos conflitos interpessoais decorre, fundamentalmente, das diferenças de traços de personalidade, tanto na esfera familiar quanto no trabalho, as quais são percebidas durante a convivência diária e diferenças em informações e percepções, pois as pessoas recebem informações e as retêm de maneiras diferentes, interpretando-as de formas distintas, o que pode ocasionar, ao trocarem essas informações, algum tipo de divergência pelo modo a qual foi exposta, apesar de ser a mesma informação (NASCIMENTO, 2012).

Nessa linha, observam-se, mais facilmente, elementos externos como faixa etária, nível de escolaridade formal e tempo de experiência no negócio, os quais podem modelar as diferentes visões e opiniões dos sócios sobre o negócio. No caso da ImpreX, em relação à faixa etária, são duas gerações compartilhando a responsabilidade pela gestão, dado que, à época da sucessão, as idades de Breno e Lucas eram 21 e 23 anos, respectivamente, ao passo que Heloísa havia completado 50 anos de idade. Quanto ao nível de escolaridade formal, Breno cursava a graduação em administração, Lucas já concluíra a graduação em ciência da computação e

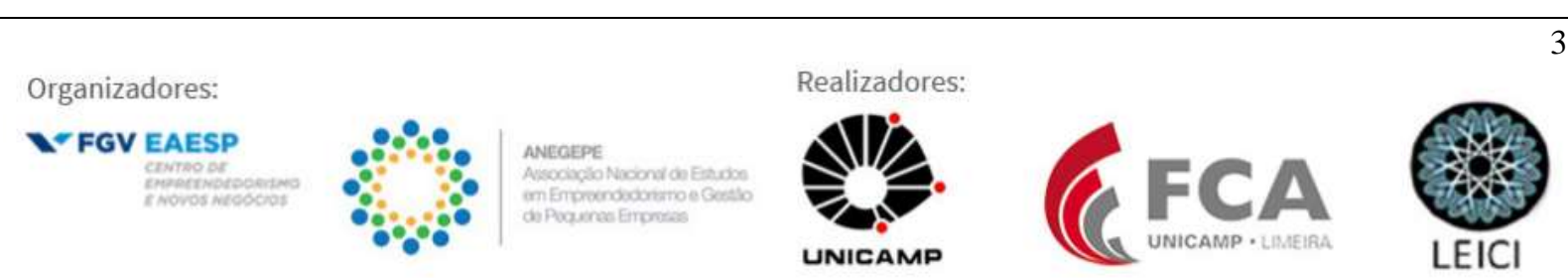


Heloísa concluído, apenas, o ensino médio. Pondera-se também sobre o tempo de experiência na empresa, pois pessoas que estão há mais tempo na organização tendem a tomar conhecimentos, crenças e formas de tomar decisões, usados no passado, como parte de um quadro de referência da ação gerencial, contribuindo para a consolidação de ideias dominantes e comportamentos rígidos (BETTIS; PRAHALAD, 1986). Diferentemente de Breno e Lucas, que estavam mais voltados a resolver os problemas da empresa por meio de novas abordagens, Heloísa tinha a tendência a propor as estratégias às quais estava habituada.

Um dos principais dilemas das empresas familiares é a equalização dos diversos sistemas de interesses relacionados à família, à estrutura de propriedade e à estrutura de gestão, de modo a permitir o gerenciamento tanto dos interesses coletivos quanto dos individuais (MOREIRA, 2011). Logo, para que os conflitos, nessas organizações, sejam administrados dentro de um entendimento razoável, as pessoas envolvidas devem adotar uma atitude de abertura para diálogo. A administração das situações de conflitos é o ponto de partida para a identificação de novas formas de se resolver um problema e se alcançar o resultado desejado, permitindo a aquisição de novas aprendizagens e proporcionando a mudança necessária para o desenvolvimento individual e organizacional (ROBBINS, 2006).

\section{Análise da situação-problema e proposta de intervenção}

A proposta de intervenção na ImpreX, objeto do presente estudo, ocorreu por meio da mediação, visando a contenção dos conflitos existentes na empresa. A mediação é um método de solução de conflitos flexível e não obrigatório no qual as partes envolvidas recebem a intervenção de uma terceira pessoa neutra, o mediador, que contribui para que as pessoas interessadas alcancem possibilidades para a solução da disputa, em que ambas fiquem satisfeitas (BUSH; FOLGER, 1996, HIGTON; ÁLVAREZ, 1999).

Espera-se que o comportamento do mediador seja voltado para propiciar um novo encontro entre as pessoas envolvidas num conflito, que, no âmbito da intervenção, são as protagonistas da resolução desse (SALES, 2004). Isto quer dizer que o mediador não possui um papel impositivo; pois ele "[...] facilita a comunicação, promove o entendimento, leva as partes a se focarem em seus interesses e procura soluções criativas que deixem as partes livres para chegar a um acordo próprio" (KOVACH; LOVE, 2004, p.107).

Desse modo, a mediação realizada na ImpreX foi conduzida por um consultor externo, a convite dos sócios da empresa. Sua principal responsabilidade foi a de auxiliar e direcionar os diálogos necessários, desde as causas dos mais variados conflitos internos até a condução de um plano de ação exposto consensualmente pelos sócios.

O processo envolveu a realização de apenas uma reunião de trabalho, com duração de quatro horas e contou com a participação do mediador e dos três sócios. A reunião foi estruturada e orientada em três tópicos principais: o primeiro tópico consistiu na coleta de opiniões individuais dos membros acerca dos problemas e conflitos existentes; em seguida, compilou-se os cinco principais conflitos em comum apresentados pelos sócios e, posteriormente, cada um deles proferiu sugestões de solução para os conflitos compilados. Dessa forma o mediador pode elaborar um plano de ação baseado nas sugestões apresentadas pelos sócios, com o intuito de promover, consensualmente entre eles, ações para remediar, minimizar ou solucionar os conflitos compilados, indicados como principais e com maior incidência no dia-a-dia da organização.
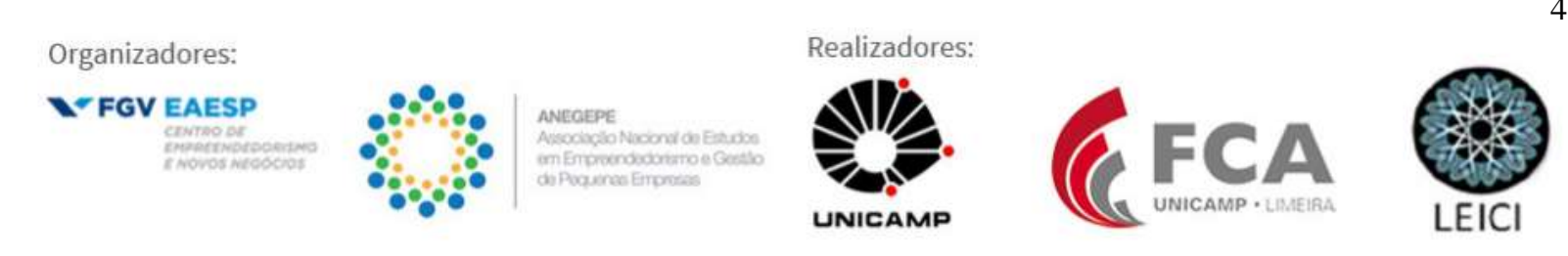
A reunião de mediação da empresa ImpreX, começou com o mediador solicitando para que cada sócio apresentasse os conflitos que julgavam mais frequentes e importantes juntamente com os motivos que ocasionavam a situação de desgaste. O mediador conduziu o processo, determinando que todos tivessem seu momento exato de argumentar, para que a reunião não tivesse desvio de foco, desentendimentos ou discussões.

Heloísa apresentou algumas questões a serem observadas que ela julga muito importantes. Ela apontou que sente dificuldades no relacionamento com os filhos dentro da organização por ter praticamente o dobro da idade deles, possuindo uma visão diferente para cada situação na empresa, e que, na maioria das vezes, não consegue desvencilhar o papel de mãe, mesmo nas situações de trabalho ou discussões com os filhos e, ao mesmo tempo, sócios.

Para Lucas, um dos principais fatores que contribuem para que existam diversos e constantes conflitos entre os familiares é que a organização não goza de uma estrutura funcional adequada e profissionalizada, de modo que a hierarquia possa exercer seu papel. Lucas afirmou que como todos os membros do corpo gestor da empresa são familiares, as discussões e argumentações transcendem a simples aceitação de opiniões divergentes, pois, por serem membros familiares, é como se não existisse um fim para a discussão, como se ainda houvesse sempre recursos para tentar mudar a opinião do outro sócio para vigorar a sua própria opinião, considerada como a mais correta por cada um.

Já Breno apresentou que na empresa não se aplica muitas regras "básicas", ou seja, que são fundamentais para o melhor andamento das atividades e diminuição de muitos conflitos. Ele considera que empresas familiares pouco estruturadas e com estrutura informal realmente não possuem a aplicação rígida de tais regras e isso compromete o nível emocional dos membros familiares. Alguns apontamentos de Breno são: não há regra definida para atrasos e faltas de funcionários; para quais setores ou se em todos os setores da empresa deve-se coibir o uso de aparelhos eletrônicos e nem para a gestão dos erros de produção causados por funcionários. Breno ainda aponta que existe uma enorme dificuldade e mal-estar em realizar cobranças relacionadas às funções desempenhadas pelos outros sócios.

Diante da exposição dos argumentos apresentados por cada um dos membros, muitos problemas foram elucidados. Foi possível elencar, em grau de importância, cinco diferentes conflitos a serem analisados separadamente na visão de cada um dos sócios, para que, ao final, fosse possível apresentar medidas para diminuir os conflitos gerados por esses fatores.

A seguir, descreve-se os cinco potenciais geradores de conflitos apresentados consensualmente pelos membros familiares da organização e objetos passíveis da proposta de mediação na empresa ImpreX: a) falta de solução para várias situações rotineiras; b) refazer ou não determinado serviço com erro de produção; c) delegação de atividades diferentes para um mesmo subordinado por membros diferentes da família, gerando dúvidas nesse colaborador sobre qual atividade realizar primeiro; d) descontrole financeiro, mistura de contas físicas com contas jurídicas; e) divergência de personalidades perante as eventuais situações diárias.

Analisando primeiramente a situação descrita no primeiro problema, "falta de solução para várias situações rotineiras", estas podem ser melhor compreendidas e exemplificadas com as seguintes situações: punição de funcionário que cometeu qualquer irregularidade; funcionário faltar ao serviço; funcionário utilizando aparelho celular durante o expediente de trabalho ou fazendo qualquer outra atividade que não seja o exercício da função; participação
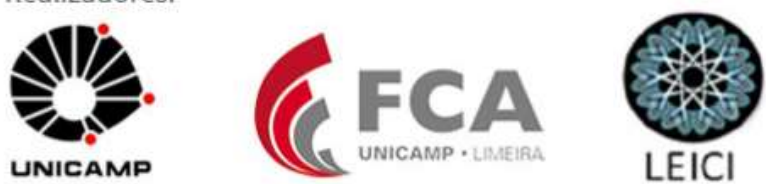
da empresa em eventos patrocinados ou realização de parcerias, quando não há a concordância de todos, dividindo as opiniões e, por vezes, gerando brigas e discussões.

O que foi descrito no segundo problema, "refazer ou não determinado serviço com erro de produção", relaciona-se com as eventuais falhas no processo produtivo ocasionadas por erro de algum funcionário em exercício da função ou, em virtude de alguma eventualidade no decorrer da atividade produtiva. São decisões que não podem ser postergadas, necessitam de atenção imediata, diferentemente das decisões apresentadas no item 1, em que não existe a demanda de uma ação imediata.

Em relação ao terceiro problema, "delegação de atividades diferentes para um mesmo subordinado por membros diferentes da família, gerando dúvidas nesse colaborador sobre qual atividade realizar primeiro", é abordado o conflito de delegações recebidas por um mesmo funcionário, que fica em dúvida sobre qual atividade ele deve executar primeiro. Nessa situação, os sócios apresentaram uma ocorrência em que Breno, gerente de produção, havia determinado um limite mínimo de dias de produção para o trabalho x, e Heloísa, algumas vezes, autorizava determinada funcionária a vender o mesmo trabalho x em menor quantidade de dias devido à forma de pagamento apresentada pelo cliente, anulando, de certa maneira, a determinação estabelecida por Breno visando o controle organizado da produção.

Já, sobre o quarto problema relatado, "descontrole financeiro, mistura de contas físicas com contas jurídicas", é uma falha típica, reconhecida por Heloísa, que acarreta vários conflitos devido às más práticas de utilizar recursos de contas físicas para justificar as oscilações de datas em que recursos da empresa serão debitados na conta jurídica.

Por fim, no quinto problema, "divergência de personalidades perante as eventuais situações diárias", estas são geradoras de conflitos quando em determinada situação, a atitude de um dos membros é repudiada pelos outros dois. Um exemplo citado foi o mau trato de Heloísa direcionado a um cliente em ligação telefônica, por ele querer retirar o serviço contratado na empresa, em que já havia efetuado uma entrada em dinheiro no momento da venda e queria efetuar o pagamento posteriormente, em desacordo com o combinado inicial. Heloísa, ao invés de argumentar e apresentar os motivos da não liberação, perdeu a paciência e destratou o cliente. Outras situações de conflitos geradas entre os membros devido à diferentes personalidades são as discussões e atritos com funcionários. Breno possui uma personalidade forte e sempre que existe algum conflito com algum funcionário, facilmente perde a razão.

O mediador, como parte da proposta de intervenção, e, visando uma melhor compreensão do processo por parte dos gestores familiares, solicitou para que cada um, diante dos cinco problemas apresentados como geradores de conflitos, apresentasse argumentos que julgassem importantes a serem adotados para minimizar ou sanar a existência daquele conflito.

No primeiro problema apresentado, "falta de solução para várias situações rotineiras", Heloísa julgou válido realizar votações entre os três membros, de modo que duas opiniões iguais prevaleceriam e seria a decisão a ser tomada. Ela considerou também ser necessário delegar completamente a tomada de decisões por áreas de atuação dos membros familiares, para que não houvesse intervenções entre os membros nas decisões. Já Breno apontou que seria necessário especificar dia e horário para conversar unicamente para resolver aquela determinada situação rotineira; e Lucas, mencionou que seria adequado dividir o ambiente de trabalho em salas separadas, para que, se preciso, possam conversar a sós, visando a melhoria nos diálogos e argumentações.
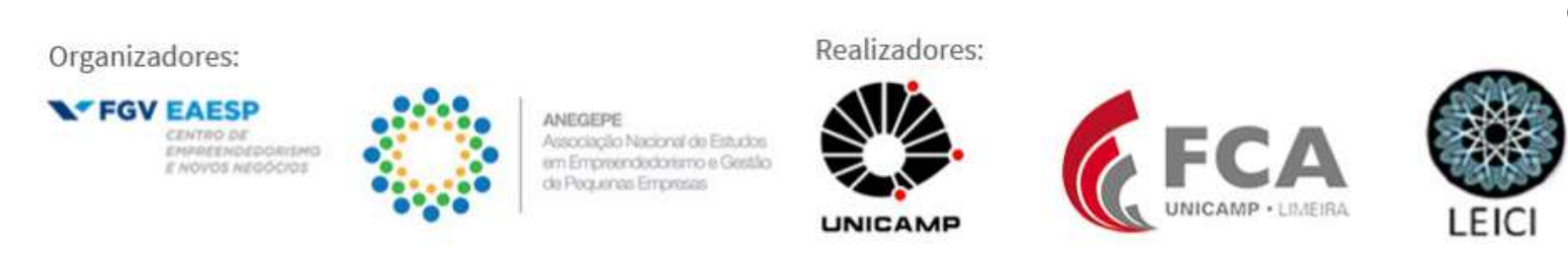
Com relação ao segundo problema, "refazer ou não determinado serviço com erro de produção", Heloísa defendeu ser preciso descontar o prejuízo do funcionário culpado pelo erro e considerou indispensável realizar reuniões frequentes com os colaboradores para conscientizá-los sobre as proporções de cada erro. Lucas é contra o desconto do prejuízo diretamente do funcionário, pois acredita atrapalhar a harmonia da organização e também apontou que tal situação esbarra no aspecto legal, pois, para que haja o desconto do funcionário que voluntariamente causou o erro, é preciso que ele concorde previamente com tal posição da empresa. Ele mencionou também que deve ser feito um plano de ação para evitar erros. Se o erro foi causado por falta de atenção, o motivo deverá ser bloqueado, se o motivo foi desleixo ou negligência, será preciso advertir o funcionário para diminuir futuras ocorrências. Breno colocou que para não gerar conflitos perante os erros deve-se decidir de imediato pela alternativa que apresente o melhor custo $\mathrm{x}$ benefício, e ainda, que seja elaborado uma tabela com o registro dos erros para influenciar na quantidade de reuniões de conscientização.

Para diminuir os conflitos gerados pelo terceiro problema, "delegação de atividades diferentes para um mesmo subordinado por membros diferentes da família, gerando dúvidas nesse colaborador sobre qual atividade realizar primeiro", Lucas propôs que sejam definidas as reais funções, áreas e atribuições que cada um dos sócios ficará responsável, de forma que cada um possa delegar funções da área de sua responsabilidade. Dessa forma, para que haja qualquer intervenção que outro membro julgue ser válida, será preciso ser autorizada pelo membro responsável por aquele determinado setor. Heloísa é totalmente a favor da proposta sugerida por Lucas e Breno também concordou e apresentou a opinião de que, na falta do responsável pela atribuição e delegação daquele determinado setor, que qualquer um dos outros dois membros da família possa delegar em sua ausência.

Já sobre o quarto problema, "descontrole financeiro, mistura de contas físicas com contas jurídicas", para Lucas, os conflitos seriam sanados com a separação completa das contas de pessoa física e jurídica. Breno e Heloísa concordam com Lucas. Heloísa apontou que tem consciência de que é preciso trabalhar dessa forma, e alegou que não realiza essa prática por que quer, mas por que precisa, devido a várias situações e divergências de fluxos de caixa, para socorrer problemas financeiros diários.

Por último, com relação aos conflitos provenientes do quinto problema, "divergência de personalidades perante as eventuais situações diárias", Heloísa defendeu a ideia de burocratizar todos os processos, definido regras específicas e responsabilidades como: determinação de quem atenderá o telefone e de quem solucionará problemas de Recursos Humanos, etc. Lucas é contra, pois, ele defende a desburocratização para o melhor curso das atividades na empresa. Ele julgou importante realizar uma reunião entre os membros da família para definir as principais atribuições e regras de cada um nas mais variadas situações e deixar algumas variáveis a cargo dos responsáveis pelo setor. Por exemplo: cliente quer pagar o serviço com parcelamento em " $n$ " vezes - essa decisão seria melhor tomada por Heloísa, gerente financeira; vendedora vender o serviço errado comprometendo a produção - ao invés de Breno, gerente de produção, querer resolver o problema, Lucas intermediaria essa situação para solucionar o problema de forma mais adequada. Para Breno, diante de situações relacionadas aos conflitos provenientes do quinto problema seria adequado registrar as ocasiões geradoras destes e discutilas em reuniões para conscientizar o membro que agiu de forma errada a não repetir o mesmo comportamento.
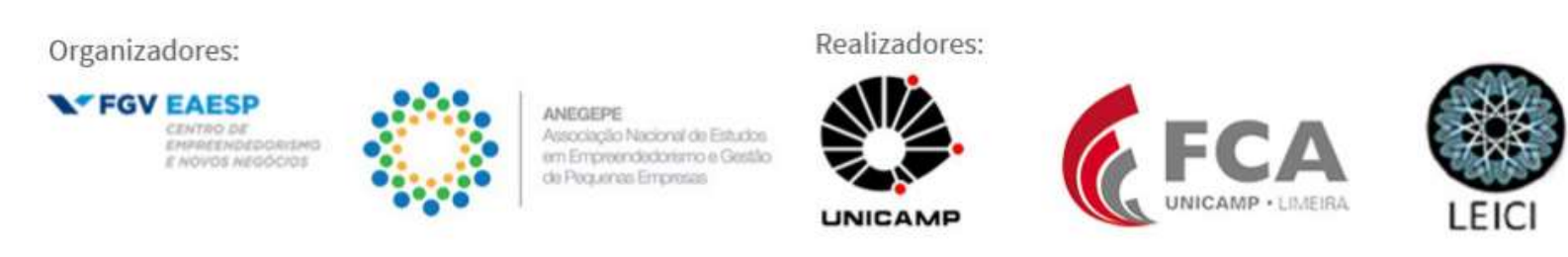
Após apresentados os principais geradores de conflitos pelos membros familiares no processo de mediação e elucidadas as possíveis ações na visão de cada um dos membros gestores da empresa, o mediador propôs aos membros que entrassem em consenso perante as ações para resolução dos conflitos propostas por cada um deles, visando a construção de um plano de ações que os próprios sócios e membros familiares começarão a implementar após a intervenção da mediação, para auxiliá-los na melhor gestão dos futuros conflitos. A proposição sugerida pelo mediador pode ser embasada pelo pensamento de Ávila (2002), que apresenta a mediação familiar como um método de gerenciamento e resolução de conflitos por meio da cooperação e não da intimidação. As decisões são tomadas pelos envolvidos e não pela imposição de um terceiro e o acordo gerado deve refletir alternativas criativas ao invés de uma situação em que exista um inocente/ganhador e um culpado/perdedor.

A seguir, o quadro 1 contempla o plano de ações acordado entre os membros familiares para cada uma das situações abordadas:

Quadro 1: Plano de ações para minimizar os potenciais geradores de conflitos na ImpreX

\begin{tabular}{|c|c|}
\hline Potenciais geradores de conflitos & Ações de melhoria \\
\hline $\begin{array}{l}\text { Falta de solução para várias situações } \\
\text { rotineiras }\end{array}$ & $\begin{array}{l}\text { - Especificar dia e horário para conversar única e exclusivamente } \\
\text { para resolver determinada situação rotineira; } \\
\text { - Realizar a divisão do ambiente de gestão em salas separadas, para } \\
\text { que possam conversar a sós, visando a melhoria nos diálogos e } \\
\text { argumentações. }\end{array}$ \\
\hline $\begin{array}{l}\text { Refazer ou não determinado serviço } \\
\text { com erro de produção }\end{array}$ & $\begin{array}{l}\text { - Realizar frequentes reuniões com todos os colaboradores para } \\
\text { conscientizá-los sobre as proporções de cada erro; } \\
\text { - Elaborar diretrizes padrão para evitar erros, ou seja, solucionar o } \\
\text { erro pela raiz; } \\
\text { - Analisar a exatidão da causa geradora do erro e decidir de } \\
\text { imediato pela melhor alternativa que apresente o melhor custo x } \\
\text { benefício; } \\
\text { - Elaborar uma tabela com o registro de todos os erros para } \\
\text { influenciar na quantidade de reuniões de conscientização. }\end{array}$ \\
\hline $\begin{array}{l}\text { Delegação de atividades diferentes para } \\
\text { um mesmo subordinado por membros } \\
\text { diferentes da família, gerando dúvidas } \\
\text { nesse colaborador sobre qual atividade } \\
\text { realizar primeiro }\end{array}$ & $\begin{array}{l}\text { - Definir as reais funções, áreas e atribuições que cada um dos } \\
\text { membros gestores ficará responsável, de forma que cada um será } \\
\text { responsável por delegar decisões da área em que atua e será por } \\
\text { ela responsável; } \\
\text { - Na falta do responsável pela atribuição e delegação daquele } \\
\text { determinado setor, qualquer um dos outros dois membros da } \\
\text { família poderá delegar em sua ausência. }\end{array}$ \\
\hline $\begin{array}{l}\text { Descontrole financeiro, mistura de } \\
\text { contas físicas com contas jurídicas }\end{array}$ & $\begin{array}{l}\text { - Realizar a separação minuciosamente completa das contas de } \\
\text { pessoa física e jurídica. }\end{array}$ \\
\hline $\begin{array}{l}\text { Divergência de personalidades perante } \\
\text { as eventuais situações diárias }\end{array}$ & $\begin{array}{l}\text { - Realizar a desburocratização para o melhor curso das atividades } \\
\text { na empresa; } \\
\text { - Realizar uma reunião entre os membros para definir as principais } \\
\text { atribuições e regras de cada membro da família para ficar a cargo } \\
\text { dos responsáveis por aquele setor; } \\
\text { - Realizar um registro das ocasiões desagradáveis ocorridas devido } \\
\text { as diferentes personalidades e discuti-las em reuniões futuras para } \\
\text { conscientizar o membro que agiu de forma errada a não repetir tal } \\
\text { comportamento. }\end{array}$ \\
\hline
\end{tabular}

Fonte: Elaborado pelos autores, com base nos dados coletados, na pesquisa. 
As organizações familiares vislumbram constantemente a existência de conflitos que por ventura prejudicam o clima organizacional, impactam a produtividade do empreendimento e comprometem a harmonia interna da empresa. Em razão disso, para que restaurem rapidamente ou adotem medidas preventivas de conflitos, é fundamental a adoção da mediação como forma de solucionar os conflitos inerentes ao convívio familiar e empresarial.

Nesse contexto, Moore (1998), apresenta que a mediação vem sendo difundida, pelo reconhecimento de que amplia as possibilidades de as partes continuarem seu relacionamento de maneira pacífica no futuro e também por sua capacidade de promover a participação democrática nos níveis familiares, sociais e políticos, assegurando o respeito à diversidade.

\section{Considerações finais}

O objetivo, neste artigo, foi relatar o processo de mediação realizado numa empresa familiar, com a finalidade de identificar as causas dos conflitos interpessoais entre os membros da família e de propor ações de melhoria. Esse processo de intervenção possibilitou uma análise das principais causas dos conflitos apresentados pelos membros familiares e orientou-os a um plano de ação a ser adotado futuramente em seus relacionamentos, visando a minimização ou a facilitação de gestão desses possíveis futuros conflitos.

Com base nos resultados alcançados, as ações provenientes de um processo de mediação, realizado no contexto de uma empresa familiar, mostraram-se relevantes para o seu desenvolvimento, pela facilitação do diálogo entre as partes envolvidas, apresentando possíveis orientações e direcionamentos imparciais para que os próprios integrantes do conflito consigam encontrar soluções benéficas e satisfação mútua. As pessoas em conflito, por intermédio da atuação do mediador, chegaram a um acordo considerado ideal da forma mais pacífica possível, favorecendo um melhor relacionamento entre os membros familiares em conflitos futuros.

O presente trabalho contribui para induzir outras empresas familiares adotem processos estruturados para lidar com os conflitos, como o exemplo da mediação, adotado no presente estudo. Dessa forma, as organizações familiares, ao buscarem a profissionalização da gestão de seus conflitos provenientes da atividade empresarial, poderão, eventualmente, apresentar mais capacidade competitiva e, assim, impactar positivamente na redução das taxas de mortalidade das empresas familiares de pequeno porte.

É preciso que os sócios e membros familiares desse tipo de constituição empresarial analisem a viabilidade, necessidade e frequência desses conflitos e, principalmente, do impacto que esses conflitos, por ventura, estejam causando nas relações familiares.

Por fim, esse trabalho possui algumas limitações que se apresentam como oportunidades para estudos futuros. Sugere-se a realização de um acompanhamento, a longo prazo, se as medidas apresentadas no plano de ação como consequência do processo de mediação estão sendo realmente aplicadas e bem-sucedidas na pacificação dos conflitos entre os membros da família desse estudo e, também, a aplicação desse mesmo processo em algumas outras empresas familiares do mesmo porte para analisar a eficiência desse processo de intervenção e gestão de conflitos.

\section{Referências}

ÁVILA, E. M. Mediação familiar. Tribunal de Justiça de Santa Catarina. Florianópolis: Divisão de Artes Gráficas do Tribunal de Justiça de Santa Catarina, 2002.

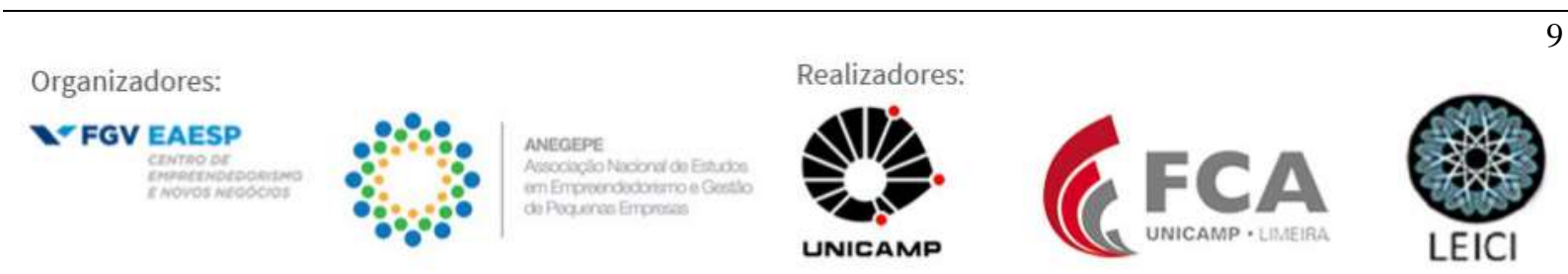


BARRETO, M. G. P.; BARRETO, E. F. A mediação como instrumento para resolução de conflitos nas empresas familiares. Revista Brasileira de Administração Política, v. 7, n. 2, p. 149-160, 2014.

BERNHOEFT, R. Empresa Familiar: sucessão profissionalizada ou sobrevivência comprometida. São Paulo: Nobel, 1989.

BETTIS, R. A.; PRAHALAD, C. K. The dominant logic: a new linkage between diversity and performance. Strategic Management Journal, v. 7, p. 485-501, 1986.

BORNHOLDT, W. Governança na empresa familiar: implementação e prática. Porto Alegre: Artmed, 2005.

BRITO, M. J.; SILVA, S. S.; MUNIZ, M. M. J. The Meanings of the Death of the Founder: The Constructionist Approach. Brazilian Administration Review, v. 7, p. 227-241, 2010. BUSH B.; FOLGER, J. P. La promessa de mediación. Buenos Aires: Granica, 1996. CÉZAR-FERREIRA, V. A. Família, separação e mediação: uma visão psicojurídica. São Paulo: Editora Método, 2004.

DONNELEY, R.G. The family business. Harvard business Review, v. 42, n. 4, p. 94-105, 1967.

KOVACH, K. \& LOVE, L. Mapeando a Mediação: Os Riscos do Gráfico de Riskin. In AZEVEDO, A. G. (Org.) Estudos em arbitragem, mediação e negociação. Brasília: Grupos de Pesquisa, 2004.

HIGHTON, E. I.; ÁLVAREZ G. S. A mediação no cenário jurídico: seus limites - a tentação de exercer o poder e o poder do mediador segundo sua profissão de origem. In SCHNITMAN, D.; LITTLEJONH. Novos Paradigmas em mediação. Porto Alegre: Artmed, 1999.

LEACH, P. Family Business. London: Stoy Hayward, 1994.

LEONE, N. A sucessão não é tabu para os dirigentes da PME. In: ENCONTRO DA ANPAD, 15., 1991, Belo Horizonte. Anais... Belo Horizonte: Anpad, 1991.

LODI, J. B. A empresa familiar. 4. ed. São Paulo: Pioneira, 1993.

LONGENECKER, J. et al. Administração de pequenas empresas. São Paulo: Makron, 1997.

MARTINS, M. C. F.; ABAD, A. Z.; PEIRÓ, J. M. Conflitos no ambiente organizacional. In: SIQUEIRA, M. M. M. (Org.). Novas medidas do comportamento organizacional. Porto Alegre: Artmed, 2014.

MOREIRA, A. L. Bastidores da empresa familiar: como reduzir os conflitos por meio da governança corporativa. 1. ed. São Paulo: Atlas, 2011.

MOORE, C. W. O processo de mediação. 2. ed. Porto Alegre: Artmed, 1998.

NASCIMENTO, E. Comportamento organizacional. 1. ed. Curitiba: IESDE, 2012.

POUTZIOURIS, P. The strategic orientation of owner-managers of small ventures: evidence from the UK small business economy. International Journal of Enterpreneurial Behavior and Research, v. 9, n. 5, p. 185-214, 2003.

ROBBINS, S. P. Comportamento organizacional. 11. ed. São Paulo: Prentice Hall, 2006. SALES, L. M. M. Justiça e mediação de conflitos. Belo Horizonte: Delrey, 2004. 